but since, according to Lebert, epithelioma develops in 12 per cent. the lip was removed with a margin of sound skin around the growth and healed subsequently without trouble. There was no glandular affection and no sign or history of syphilis. I made no section of the lip, as it was preserved for museum purposes. Like most platelayers the patient smoked much.

Carlisle.

\section{CASE OF SEVERE HEAT-STROKE; RECOVERY.}

BY J. W. CRAWSHAW, M.B., Ch.B. VICT.,

LATE SURGLON, OCEAX STEAM TATIGATION COMPAXY.

IN The LANCET of April 4th Mr. P. J. Atkey reported a case of severe heat-stroke in which the temperature reached $108.2^{\circ} \mathrm{F}$. and the patient recovered without any ill effects. In May, 1894, while acting as surgeon on board the Ocean Steam Navigation Company's s.s. Pyrrhus I had a somewhat similar case, which recovered very rapidly. The following account of the case is taken from my entries made at the time in the surgeon's log-book.

On May 28th, 1894, while in the Indian Ocean some 300 miles to the westward of Ceylon an English youth aged seventeen years was taken ill. He had been working nearly the whole day directly exposed to the heat of the sun. He never complained of any illness, but at 4.30 P.M. he was noticed to stagger and fall. Some of the men went to his assistance, found him very ill, and at once sent for me. I found him quite conscious, and he complained of violent headache and pains in the back and limbs. His skin was very hot and dry and his pulse was very rapid, full, and bounding. I placed my thermometer beneath his tongue, but by the time the temperature was taken he was quite comatose. The thermometer registered $108^{\circ}$. The method I adopted to reduce the temperature was very rough and simple, but proved very effective. I had the lad stripped as rapidly as possible and laid on the deck. A large piece of ice was placed to his head and sea water was brought in buckets and dashed over him in an almost continuous stream. After about twenty minutes of this treatment the temperature had fallen to $103^{\circ}$ and the lad had recovered consciousness and expressed himself as feeling much better. The douching was discontinued, he was placed in his bunk and given hot tea to drink. A powder consisting of five grains of calome and twenty grains of antipyrin was given. An hour later I found the patient's temperature had again risen to $105^{\circ}$ and he was very drowsy. $\mathrm{He}$ became unconscious again and had a violent convulsion. The cold douching was recommenced in the same manner and continued for some time until the temperature fell to $100 \cdot 4^{\circ}$. He again recovered consciousness and was placed under awnings on the hatch, where he was much cooler than in the forecastle. He felt much better and was able to partake of a little milk food. The temperature afterwards rose to $103^{\circ}$, but no higher. The skin continued hot and dry and a diaphoretic mixture was given. He passed rather a restless night, but on the next morning, the 29th, he felt fairly comfortable. His temperature was $101^{\circ}$. He had micturated very frequently during the night and the skin was still very dry. The bowels had not been moved, so two ounces of mistura sennæ composita were given. At 9 P.M. the tem. perature was normal. On the 30 th he was much better. The temperature was normal the whole day and the skin moist. The bowels were well opened. On the 31 st he felt quite well. He had no headache, dizziness, or other unpleasant symptom, and was allowed to resume his work. Throughout the remainder of the voyage he remained perfectly well, but was careful not to expose himself to the sun.

I can quite endorse all that Mr. Atkey says about the good chance these cases have on board ship. The surgeon cannot be far away and ice and water at a suitable temperature are plentiful. Much delay in a case like the above would greatly diminish the prospects of recovery. From the time when the patient was first noticed to be ill to the commencement of the douching ten minutes conld not have elapsed, and it was undoubtedly this prompt treatment which saved his life. Dr. Wales of Canton was on board at the time and his experience of these cases was of great assistance to me. Broadbottom, Cheshire.

\section{A attirtor}

\section{H O S P I T L P R A C T I E, BRITISH AND FOREIGN.}

Nulla autem est alia pro certo noscendi via, nisi quamplurimas et morborum et dissectionum historias, tum aliorum tum proprias collectas habere, et inter so

\section{LONDON HOSPITAL.}

A CASE OF CHRONIC INVERSION OF THE UTERUS ; CIRCUMSCRIBED SLOUGHING CAUSED BY AVELING'S REPOSITOR; SUBSEQUENT REDUCTION.

(Under the care of Dr. HERMAN.)

THERE appears to have been some uncertainty about the cause of the inversion in this case, and it is not possible now to say definitely what produced it. The treatment by Aveling's repositor was effectual as it has proved in so many cases recorded in our columns, but in this instance it produced a limited slough of the uterus. There are two important points to bear in mind when applying continuous elastic pressure for inversion: the pressure must act in the line of the axis of the inverted uterus and likewise of the axis of the pelvic brim and there must be effective counter pressure. Again, the pressure must be carefully regulated and the apparatus replaced in position as often as the restlessness of the patient makes it necessary. If these precautions are taken the inversion will usually be reduced in a few days, although in one recorded instance reduction was not effected for three weeks. For the notes of this case we are indebted to Dr. G. H. Cowen, resident accoucheur, and Mr. E. C. Davenport, clinical clerk.

The patient, aged thirty-one years, was admitted on Dec. 31st, 1895. She said that she had always enjoyed good health until her last confinement five months ago. On this occasion (the seventh) the child was a large one and was delivered by forceps. Mr. Alexander of Bromley, E., who attended her, stated that he noticed no inversion at the time, although he gave a uterine douche after delivery. He did not see ber again until the day before her admission to the hospital. The patient said that she got up on the eighth day after delivery, and while the bowels were acting "the womb came down." She replaced it herself, but lost a good deal of blood. She had no further trouble for three weeks. Then the womb "came down" again. After this she had no inconvenience except a watery discharge until a fortnight before admission, when she had severe floodings. She went to a medical man who tried to get the womb back, but failing to do so advised ber to go to the hospital. She had nursed her child until three weeks before admission. On vaginal examination there was found to be a round swelling about the size of a Tangerine orange projecting into the upper part of the vagina. It presented no opening. The sound could not be passed up by its side, nor could the body of the uterus be felt bimanually in its proper place. The urine was alkaline and ammoniacal, with a deposit of pus and phosphates. There was no other sign of disease. On Jan. 6th, 1896, Aveling's repositor was applied. Its pressure caused much pain and made the patient restless, for which reason, probably, it slipped off the fundus. Between the 6 th and 20th it was frequently applied, but each time was found to soon slip off without reducing the inversion. On the latter date it was found that there was much greenish, offensive discharge, and on this account the repositor was discontinued and an antiseptic vaginal douche given every six hours. On Feb. 11th the discharge had almost ceased. On examination the inversion was found to be less complete than at first, and a loss of substance could be felt at one part of the fundus. The repositor was reapplied. On the 12th the fundus uteri was in the normal position and there was no discharge. On the 20 th the patient was discharged well

Remarks by Dr. Herman.-The uniform success of Aveling's repositor in the treatment of chronic inversion of the uterus makes it important both to strengthen the evidence that this treatment of the rare displacement in question is the right one, and to publish cases which aid sound judgment as to the 